\title{
Synthetic Archaeosome Vaccines Containing Triglycosylarchaeols Can Provide Additive and Long-Lasting Immune Responses That Are Enhanced by Archaetidylserine
}

\author{
G. Dennis Sprott, Angela Yeung, Chantal J. Dicaire, Siu H. Yu, and Dennis M. Whitfield \\ Institute for Biological Sciences, National Research Council of Canada, 100 Sussex Drive, Ottawa, ON, Canada K1A 0R6 \\ Correspondence should be addressed to G. Dennis Sprott, dennis.sprott@nrc-cnrc.gc.ca
}

Received 6 July 2012; Accepted 23 August 2012

Academic Editor: Angela Corcelli

Copyright ( $) 2012$ G. Dennis Sprott et al. This is an open access article distributed under the Creative Commons Attribution License, which permits unrestricted use, distribution, and reproduction in any medium, provided the original work is properly cited.

\begin{abstract}
The relation between archaeal lipid structures and their activity as adjuvants may be defined and explored by synthesizing novel head groups covalently linked to archaeol (2,3-diphytanyl-sn-glycerol). Saturated archaeol, that is suitably stable as a precursor for chemical synthesis, was obtained in high yield from Halobacterium salinarum. Archaeosomes consisting of the various combinations of synthesized lipids, with antigen entrapped, were used to immunize mice and subsequently determine $\mathrm{CD}^{+}$and $\mathrm{CD}^{+}-\mathrm{T}$ cell immune responses. Addition of $45 \mathrm{~mol} \%$ of the glycolipids gentiotriosylarchaeol, mannotriosylarchaeol or maltotriosylarchaeol to an archaetidylglycerophosphate-O-methyl archaeosome, significantly enhanced the CD8 ${ }^{+} \mathrm{T}$ cell response to antigen, but diminished the antibody titres in peripheral blood. Archaeosomes consisting of all three triglycosyl archaeols combined with archaetidylglycerophosphate-O-methyl (15/15/15/55 mol\%) resulted in approximately additive CD8 ${ }^{+}$ $\mathrm{T}$ cell responses and also an antibody response not significantly different from the archaetidylglycerophosphate-O-methyl alone. Synthetic archaetidylserine played a role to further enhance the $\mathrm{CD} 8^{+} \mathrm{T}$ cell response where the optimum content was $20-30$ mol\%. Vaccines giving best protection against solid tumor growth corresponded to the archaeosome adjuvant composition that gave highest immune activity in immunized mice.
\end{abstract}

\section{Introduction}

The total polar lipids extracted from various archaea hydrate to form liposomes (archaeosomes [1]), that were developed initially to improve the drug delivery application of conventional liposomes [2-4]. These total polar lipid archaeosomes were found subsequently to have an enhanced ability over conventional liposomes to serve as adjuvants, that promoted not only the antibody response to an entrapped protein antigen [5] but also the $\mathrm{CD} 8^{+} \mathrm{T}$ cell response [6]. One mode of action could be correlated to an enhanced phagocytosis of archaeosomes compared to liposomes by various phagocytic cells [7]. This led to the observation that total polar lipids from various archaea, with their species-specific lipid structures, formed archaeosomes differing in receptor-mediated endocytosis and adjuvanticity [8].
Recently archaeol has been isolated from hydrolysed polar lipid extracts of Halobacterium salinarum to use as the lipid precursor to chemically synthesize various polar lipids, including glycolipids $[9,10]$. The lipids so generated are described as synthetic or more precisely as semisynthetic, because the lipid moiety with specific archaeal sn-2,3 and R-methyl group stereochemistry is of biological origin, whereas a polar head group may be conjugated to the free sn-1 hydroxyl of the glycerol backbone to give a new polar lipid structure. In this way a chemically-defined, synthetic archaeosome could in theory be optimized for each application. Feasibility was demonstrated by synthesizing a series of diglycosylarchaeols and testing their interactions with antigen-presenting cells to produce immune responses in vivo [9]. 
The long-lasting $\mathrm{CD} 8^{+} \mathrm{T}$ cell memory responses that are generally thought to be required for protection in intracellular pathogen and cancer vaccines are induced by certain total polar lipid archaeosomes and have been correlated to those archaeosomes having a high proportion of membranespanning caldarchaeol (tetraether) lipids $[6,11]$. In this study we explore whether synthetic archaeosome adjuvants that are based on the archaeol lipids without caldarchaeols, can provide such long-term responses. Further, we explore if synthetic archaetidylserine, previously found to interact positively with the phosphatidylserine receptor of antigenpresenting cells $[8,12]$, can augment the adjuvant activity of synthetic glycolipid archaeosomes.

\section{Materials and Methods}

2.1. Growth of Archaea. Halobacterium salinarum (ATCC 33170 ) was grown aerobically at $37^{\circ} \mathrm{C}$ in a medium modified to be an all nonanimal origin medium consisting of: $15 \mathrm{~g} / \mathrm{L}$ Phytone peptone UF (product 210931 from VWR International); $220 \mathrm{~g} / \mathrm{L} \mathrm{NaCl} ; 6.5 \mathrm{~g} / \mathrm{L} \mathrm{KCl} ; 10 \mathrm{~g} / \mathrm{L} \mathrm{MgSO}{ }_{4} \cdot 7 \mathrm{H}_{2} \mathrm{O}$; $10 \mathrm{~mL}$ of $0.2 \mathrm{~g} / 100 \mathrm{~mL} \mathrm{CaCl}_{2} ; 10 \mathrm{~mL}$ of $0.2 \mathrm{~g} / 100 \mathrm{~mL} \mathrm{FeSO}_{4}$. Growth of Haloferax volcanii (ATCC 29605) was in medium ATCC 974 at $30^{\circ} \mathrm{C}$ with $\mathrm{NaCl}$ content of $12.5 \%$ [13]. The antifoam agent used was MAZU DF 204 (BASF Canada). Biomass was grown in $20 \mathrm{~L}$ medium in a $28 \mathrm{~L}$ New Brunswick Scientific fermentor and harvested after $72 \mathrm{~h}$ growth. Lipids were extracted from the biomass with chloroform/methanol/water and the total polar lipids precipitated from the lipid extract with cold acetone [14].

2.2. Purification of Archaeol. Typically, $3.5 \mathrm{~g}$ of total polar lipid from $H$. salinarum was dissolved in $45 \mathrm{~mL}$ of chloroform/methanol $(2: 1, \mathrm{v} / \mathrm{v})$ and $190 \mathrm{~mL}$ methanol added. This mixture was cooled to $0^{\circ} \mathrm{C}$ in an ice bath, and $10 \mathrm{~mL}$ acetyl chloride added drop-wise while being stirred magnetically. Hydrolysis was accomplished by refluxing at $62^{\circ} \mathrm{C}$ for $3 \mathrm{~h}$. The mixture was cooled and the volume reduced by rotary evaporation to $100 \mathrm{~mL}$. Upon transfer to a separatory funnel, $12 \mathrm{~mL}$ water and $100 \mathrm{~mL}$ petroleum ether was added. The mixture was mixed and allowed to separate. The top ether phase containing lipid was pooled with a second ether extraction, and evaporated.

The archaeol oil obtained above was further purified by silica gel column chromatography. The oil dissolved in chloroform/methanol $(2: 1, \mathrm{v} / \mathrm{v})$ was loaded on a Silica gel 60 (Merck) column and archaeol eluted with pressure using hexane/t-butylmethylether/acetic acid (80/20/0.5, $\mathrm{v} / \mathrm{v} / \mathrm{v})$. Collected fractions were tested for archaeol by mini thin-layer chromatography using the eluting solvent, and fractions containing pure archaeol pooled and dried. The yield of archaeol from total polar lipid ranged from 43 to $53 \%$. Structural identity and purity of archaeol was confirmed by both NMR spectroscopy and electrospray ionization mass spectrometry.

2.3. Chemical Synthesis. Archaetidylethanolamine was synthesized according to [15]. Mannotriosylarchaeol, maltotriosylarchaeol, gentiobiosylarchaeol, and gentiotriosylarchaeol were synthesized according to our previous descriptions [10, 16] and structural details are shown in Figure 1. Synthesis methods for archaetidylserine can be found in Supplementary Material available online at doi:10.1155/2012/513231.

2.4. Purification of PGP. Archaetidylglycerolphosphate-O$\mathrm{CH}_{3}$ (PGP) was purified from the total polar lipids of Haloferax volcanii as described [13].

2.5. Archaeosome Vaccines. Archaeosomes were formed by hydrating $20-30 \mathrm{mg}$ dried lipid at $40^{\circ} \mathrm{C}$ in $2 \mathrm{~mL}$ PBS buffer ( $10 \mathrm{mM}$ sodium phosphate, $160 \mathrm{mM} \mathrm{NaCl}, \mathrm{pH} 7.1$ ) with ovalbumin Type VI (OVA, Sigma) as the test antigen dissolved at $10 \mathrm{mg} / \mathrm{mL}$. Vesicle size was reduced to about $100-150 \mathrm{~nm}$ diameter by brief sonication in a sonic bath (Fisher Scientific), and OVA not entrapped was removed by centrifugation from $7 \mathrm{~mL}$ PBS followed by 2 washes (200,000 xg max for $90 \mathrm{~min})$. Vesicle pellets were resuspended in $2-2.5 \mathrm{~mL}$ PBS and filter sterilized through $0.45 \mu \mathrm{m}$ Millipore filters. Sterile conditions and pyrogen-free water were used throughout.

Quantification of antigen loading was conducted by separating OVA from lipids using SDS polyacrylamide gel electrophoresis and densitometry as described [14]. Loading was based on $\mu \mathrm{g}$ protein/mg salt corrected dry weight of lipid. Average diameters based on intensity were measured using a Malvern Nano Zetasizer with a He/Ne laser (Spectra Research Corp., Ontario, Canada).

2.6. Animal Trials. C57BL/6 female mice (6-8 weeks old) were immunized subcutaneously near the tail base with $0.1 \mathrm{~mL}$ vaccines containing the equivalent of $20 \mu \mathrm{g}$ OVA, often entrapped in archaeosomes of various compositions. A booster consisting of the same vaccine and route was given on week 3. All protocols and SOPs were approved by the NRC Animal Care Committee and conducted within the guidelines of the Canadian Council on Animal Care.

2.7. Immune Responses. As a measure of the Th2 arm of $\mathrm{CD}^{+} \mathrm{T}$ cell adjuvant activity, IgG antibody raised in response to the antigen in the vaccine and collected in the sera of mice (5-6 mice/group) was quantified by Elisa according to a previous description [17]. The $\mathrm{CD} 8^{+} \mathrm{T}$ cell response was quantified by sacrificing duplicate mice/group to obtain their splenic cells. These splenic cells were assayed in triplicate for antigen-specific responses by standard Elispot and cytolytic T lymphocyte (CTL) methods [18].

2.8. Dendritic Cell (DC) Maturation Assay. Bone marrow was flushed from femurs and tibias of $\mathrm{C} 57 \mathrm{BL} / 6$ mice to isolate DCs. Cells obtained were cultured in RPMI medium supplemented with $8 \%$ fetal calf serum (R8) (Thermo Scientific HyClone, UT, USA) and $5 \mathrm{ng} / \mathrm{mL}$ of granulocyte macrophage colony-stimulating factor (ID Labs, Inc., Ont., Canada) [19]. Nonadherent cells were removed on days 2 and 4 and supplied with fresh medium. Bone marrow DCs were harvested as the nonadherent cells on day 7 . DC purity was greater than $90 \%$ based on flow cytometry 

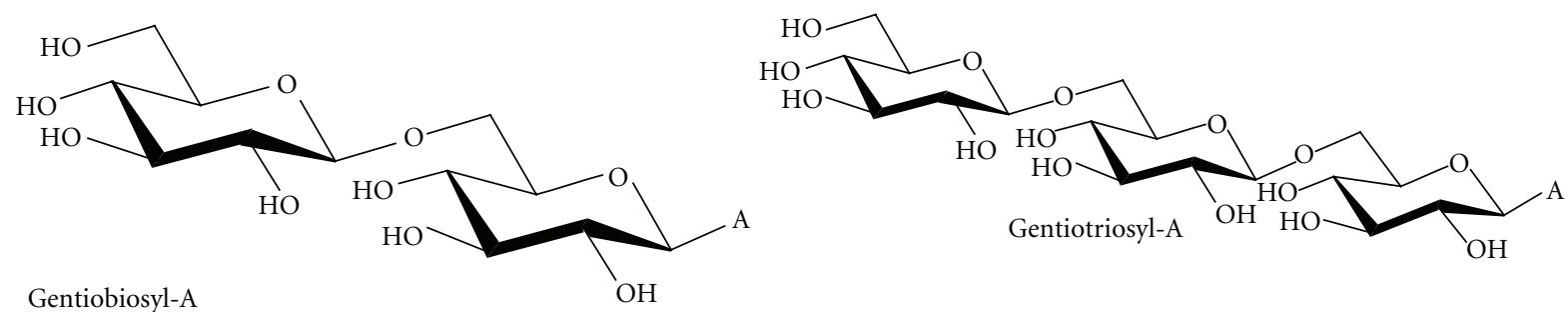

Gentiobiosyl-A
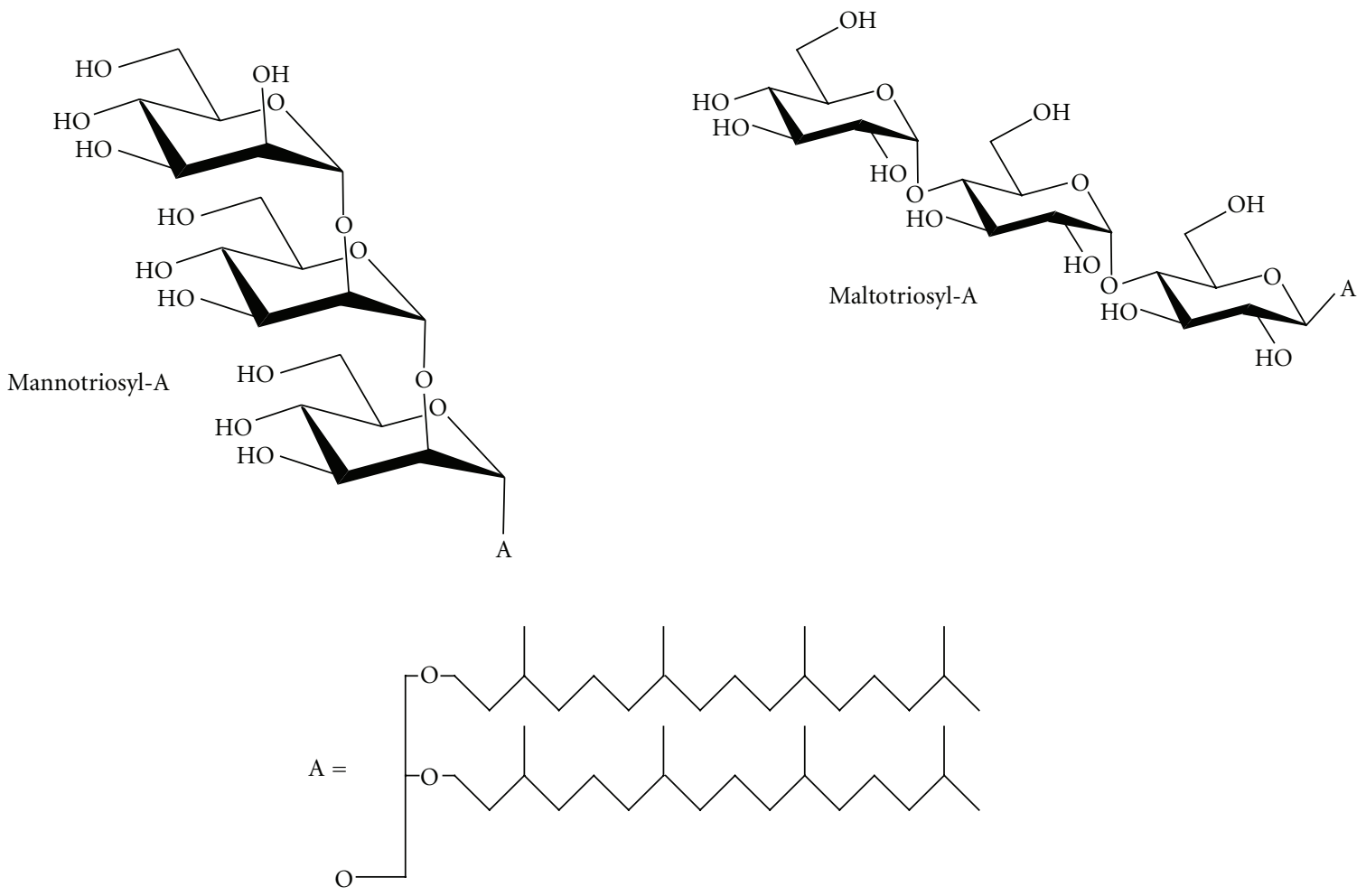

FIGURE 1: Semisynthetic glycoarchaeol structures showing head group details. "A" is the archaeol lipid precursor used for synthesis. gentiobiosyl-A $\left(\beta\right.$-Glc $c_{\mathrm{p}}-(1 \rightarrow 6)-\beta$-Glc $-(1 \rightarrow \mathrm{O})$-archaeol); Gentiotriosyl-A $\left(\beta\right.$-Glc $c_{\mathrm{p}}-(1 \rightarrow 6)-\beta$-Glc $\mathrm{c}_{\mathrm{p}}-(1 \rightarrow 6)-\beta-\mathrm{Gl} \mathrm{c}_{\mathrm{p}}-(1 \rightarrow \mathrm{O})$-archaeol); mannotriosyl-A $\left(\alpha-\operatorname{Man}_{\mathrm{p}}-(1 \rightarrow 2)-\alpha-\operatorname{Man}_{\mathrm{p}}-(1 \rightarrow 2)-\alpha-\operatorname{Man}_{\mathrm{p}}-(1 \rightarrow \mathrm{O})\right.$-archaeol); maltotriosyl-A $\left(\alpha-\mathrm{Glc}_{\mathrm{p}}-(1 \rightarrow 4)-\alpha-\mathrm{Glc}_{\mathrm{p}}-(1 \rightarrow 4)-\beta-\mathrm{Gl} c_{\mathrm{p}}-(1 \rightarrow\right.$ O)-archaeol).

of cells labeled with PE-Cy7 conjugated anti-CD11c mAb (BD Biosciences, Ont., Canada). To activate, on day 7 DCs $\left(3 \times 10^{5}\right.$ cells $\left./ \mathrm{mL}\right)$ were stimulated with $25 \mu \mathrm{g}$ of various antigen-free archaeosomes or $1 \mu \mathrm{g} E$. coli lipopolysaccharide (LPS, Sigma-Aldrich, Ltd., Ont., Canada) per $\mathrm{mL}$ in 24well plates for $24 \mathrm{~h}$. Maturation was measured by the FITCdextran (Sigma-Aldrich, Ltd., Ont., Canada) uptake assay using flow cytometry [20]. DCs were suspended in R8 medium and incubated with $1 \mathrm{mg} / \mathrm{mL}$ of FITC-dextran $(\mathrm{Mr}=40000)$ for $30 \mathrm{~min}$ at 4 or $37^{\circ} \mathrm{C}$. After incubation, the cells were washed three times with ice cold $1 \%$ sodium azide in PBS. The quantitative uptake was calculated as the change in the Mean Fluorescence Index (MFI) between cell samples incubated at 37 and $4^{\circ} \mathrm{C}$.
2.9. EG.7 Solid Tumour Model. C57BL/6 mice were immunized at 0 and 3 weeks subcutaneously with archaeosomes containing $20 \mu \mathrm{g}$ OVA. A challenge consisting of $5 \times 10^{6}$ EG.7 cells was introduced subcutaneously in the shaved lower dorsal region at either 4.5 weeks, or 14 weeks from the second immunization. Tumour progression was measured in two dimensions with a digital calliper, and values multiplied to give tumour sizes. When a tumour mass of $300 \mathrm{~mm}^{2}$ was reached the mouse was euthanized.

2.10. Statistics. A comparison of means for animal data was conducted using student's $t$-test to determine significance at 95\% confidence, and two tailed $P$ values calculated using GraphPad Prism 5. 


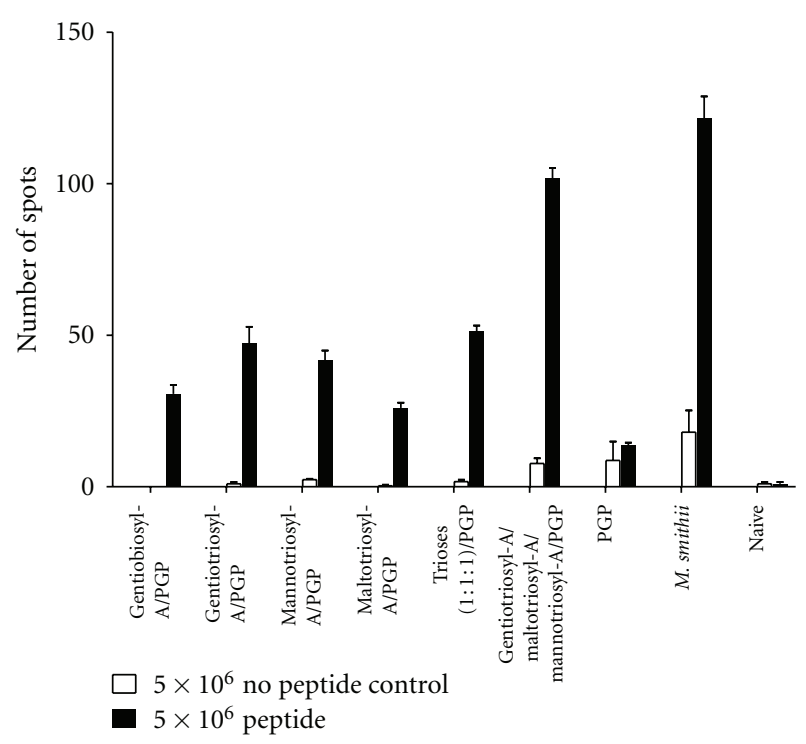

Figure 2: Antigen-specific $\mathrm{CD}^{+} \mathrm{T}$ cell activity in splenic cells of immunized mice as assayed by Elispot. Ratios of lipids in $\mathrm{mol} \%$ for various compositions of archaeosomes were: di or triglycosylarchaeols/PGP (45/55), and gentiotriosylA/maltotriosyl-A/mannotriosyl-A/PGP (15/15/15/55), where "A" refers to archaeol. Trioses $(1: 1: 1) /$ PGP refers to admixed triglycosyl-A/PGP vaccines, such that each contributed equal amounts of antigen. M. smithii represents OVA-loaded archaeosomes consisting of total polar lipids from $M$. smithii, as positive control. Mice were immunized subcutaneously at 0 and 3 weeks with OVA-loaded archaeosome adjuvants. Nonimmunized mice (naive) were included as negative controls. Spleens from duplicate mice were collected 5.5 weeks after first injection to determine the frequency (number of spots) of interferongamma (IFN- $\gamma$ )-secreting splenic cells (spots) by enzyme-linked immunospot assay (Elispot). Omission of the major CD8 epitope of OVA (SIINFEKL) from the assay (no peptide control) was used to test for nonspecific responses. Means significantly different $(P<0.05)$ were gentiotriosyl-A/PGP versus maltotriosyl-A/PGP $(P=0.0204)$, mannotriosyl-A/PGP versus maltotriosyl-A/PGP $(P=0.0135)$, and maltotriosyl-A/PGP versus PGP $(P=0.0032)$. Those not significantly different were gentiotriosyl-A/PGP versus mannotriosyl-A/PGP $(P=0.4238)$, gentiotriosyl-A/PGP versus gentiobiosyl-A/PGP $(P=0.0550)$, mannotriosyl-A/PGP versus gentiobiosyl-A/PGP $(P=0.0677)$, and gentiotriosyl-A/maltotriosyl$\mathrm{A} /$ mannotriosyl-A/PGP versus $M$. smithii $(P=0.0657)$.

\section{Results}

3.1. Synthetic Glycosylarchaeols as Adjuvants. To prepare stable glycolipid archaeosome adjuvants from neutrally charged glycosylarchaeols it was necessary to include a charged lipid. This function may be served by a conventional esterphospholipid such as phosphatidylglycerol. Although mice vaccinated with archaeosomes consisting of synthetic diglycosylarchaeols mixed with dipalmitoyl phosphatidylglycerol and antigen developed short-term $\mathrm{CD}^{+} \mathrm{T}$ cell mediated immune responses [9], longer-term responses were lost [15]. Consequently, we avoided conventional lipids in this study designed to evaluate the potential for long-term immunity from archaeol adjuvants, and chose instead an archaeolbased anionic lipid, PGP, purified from $H$. volcanii. The combination of glycosylarchaeols with PGP resulted in stable bilayers in the $100 \mathrm{~nm}$ average diameter range that entrapped the OVA antigen from $12-21 \mu \mathrm{g}$ protein $/ \mathrm{mg}$ dry weight (Table 1).

First, we tested $\mathrm{CD}^{+} \mathrm{T}$ cell responses in immunized mice using glycosylarchaeol/PGP adjuvants in short-term experiments assayed 2.5 weeks from the booster immunization (Figure 2). Elispot assays confirmed gentiotriosylarchaeol to be a better adjuvant than gentiobiosylarchaeol. Although not highly significant for the data shown here $(P=0.055)$, in other trials the difference in means was characteristically $P=0.001$. Further, both gentiotriosylarchaeol and mannotriosylarchaeol were significantly better adjuvants with PGP than was maltotriosylarchaeol. When all three triosylarchaeol vaccines were admixed in equal proportion prior to immunization the $\mathrm{CD} 8$ response was not greatly improved. However, a strikingly improved adjuvant activity, approaching the M. smithii total polar lipid positive control, was observed when the triglycosylarchaeols were incorporated into the same archaeosome preparation during hydration.

CD8 responses in mice can also be measured by cytolytic $\mathrm{T}$ lymphocyte (CTL) assays that measure the ability of effector cells in the spleens of immunized mice to lyse an EG.7 target cell line expressing the dominant epitope (SIINFEKL) of OVA. In this assay (Figure 3) the same trends as found in Elispots occurred, although maltotriosylarchaeol/PGP was less effective as an adjuvant than pure PGP archaeosomes. The combined triosylarchaeols/PGP $(45 / 55 \mathrm{~mol} \%)$ again produced an adjuvant equivalent to the total polar lipid positive control. Because of these results, we omitted maltotriosylarchaeol from further studies, and continued with the combination of gentiotriosylarchaeol/mannotriosylarchaeol/PGP.

To evaluate the ability of archaeosome adjuvants to direct antigen via antigen-presenting cells through MHC class-II presentation to $\mathrm{CD} 4^{+} \mathrm{T}$ cells (see Figure 1 of [9]), we assayed anti OVA antibody titres in the peripheral blood of mice (Figure 4). Best titres were found for PGP archaeosomes, indicating that these archaeosomes favour an MHC-II route of antigen presentation versus MHC-I (as measured by $\mathrm{CD}^{+} \mathrm{T}$ cell responses). Antibody titres for PGP were significantly higher for all adjuvants except when compared to the combination of triosylarchaeols, which was not significantly different $(P=0.056)$.

\subsection{Archaetidylserine (AS) and Archaetidylethanolamine} $(A E)$. The phosphatidylserine receptor is implicated in promoting phagocytosis of apoptotic cell debris [21] and archaeosomes [12]. Further, both archaetidylserine and archaetidylethanolamine are potentially fusogenic lipids, based on the assumption of similar activity to their ester analogs [22], and fusion of internalized archaeosomes with the phagolysosome membrane is the mechanism proposed to export antigen from archaeosomes to the MHC-I pathway 
TABLE 1: Characterization of OVA-archaeosomes.

\begin{tabular}{lcc}
\hline Archaeosome lipids & Average diameter $(\mathrm{nm})$ & OVA content $(\mu \mathrm{g} / \mathrm{mg})$ \\
\hline Gentiobiosyl-A/PGP & $153 \pm 54$ & 19.6 \\
Gentiotriosyl-A/PGP & $90 \pm 52$ & 21.1 \\
Mannotriosyl-A/PGP & $76 \pm 41$ & 16.9 \\
Maltotriosyl-A/PGP & $97 \pm 46$ & 14.7 \\
PGP & $92 \pm 54$ & 14.2 \\
M. smithii & $88 \pm 51$ & 12.0 \\
\hline
\end{tabular}

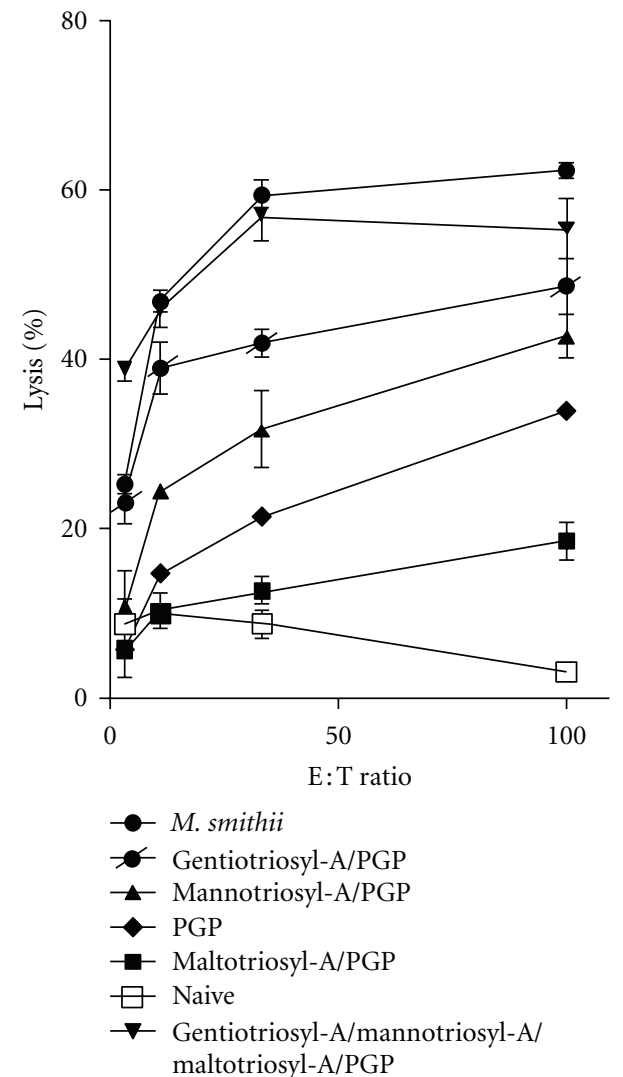

Figure 3: A cytotoxic T lymphocyte (CTL) lysis assay was used to assess the same populations of splenic cells as in Figure 1. The standard ${ }^{51} \mathrm{Cr}$ assay was conducted using specific and nonspecific target cells (EG.7 and EL-4, resp.). The ratio of effector splenic cells to target cells is shown as the $\mathrm{E}: \mathrm{T}$ ratio in the graph. Results shown are for EG.7 targets. EL-4 targets produced only low nonspecific responses (not shown).

of antigen-presenting cells [12, 23]. Consequently, importance of AS or AE incorporated into the mannotriosylarchaeol/gentiotriosylarchaeol/PGP archaeosome was assessed in terms of adjuvanting $\mathrm{CD} 8^{+} \mathrm{T}$ cell responses (Figure 5). Addition of $30 \mathrm{~mol} \%$ AS to the glycotriosylarchaeol/PGP adjuvant resulted in a significantly higher $\mathrm{CD} 8$ response $(P=$ 0.0207 ) that was not significantly different than the positive control (M. smithii). AE combined with AS had little further influence on adjuvanticity. As in other mouse trials, incorporation of glycoarchaeols to PGP archaeosomes produced a much improved $\mathrm{CD}^{+} \mathrm{T}$ cell response. In contrast, anti OVA

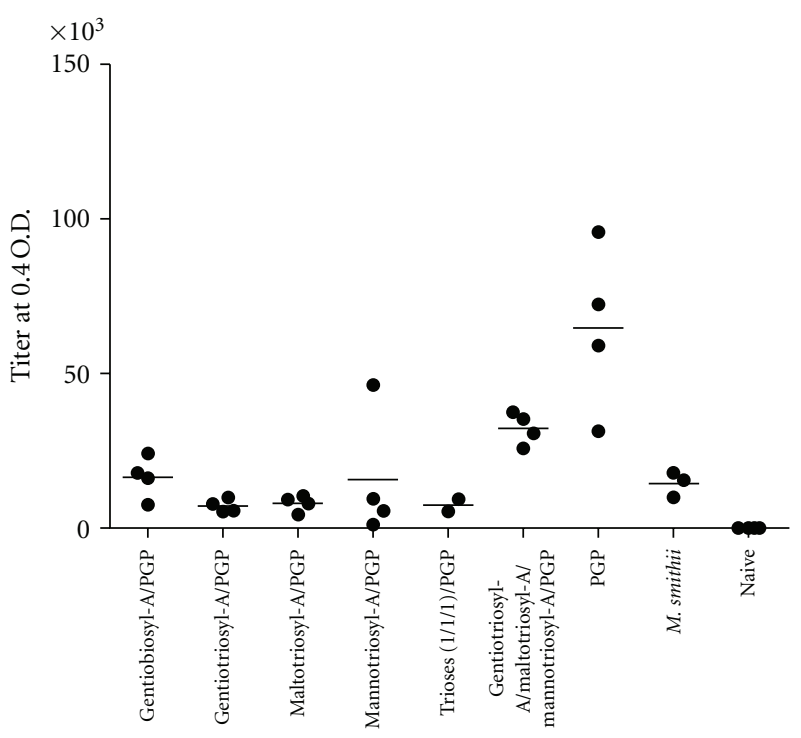

FIGURE 4: Antibody titres in sera of mice immunized with various archaeosome adjuvants. Peripheral blood was collected at 5.5 weeks, just prior to euthanizing mice for spleen removal (Figure 1). Each data point shown represents the titre in the serum from an individual mouse. Means were significantly higher for the OVAPGP archaeosome vaccinated group $(P<0.05)$ compared to all groups except for Gentiotriosyl-A/Maltotriosyl-A/MannotriosylA/PGP $(P=0.0560)$.

antibody titres in peripheral blood were not significantly higher upon inclusion of AS (data not shown).

To quantify the optimal amount of AS to adjuvant the $\mathrm{CD}^{+} \mathrm{T}$ cell mediated response, from 0 to $30 \mathrm{~mol} \%$ AS was incorporated into the triglycosylarchaeol/PGP archaeosome. Elispot assays (Figure 6) showed little effect of $10 \%$ AS, with an optimal effect of $>20-30 \mathrm{~mol} \%$. Archaeosomes could not be tested with $>30 \mathrm{~mol} \%$ AS because of instability. These findings were verified by CTL assays (Figure 7), that confirmed an adjuvant activity at $30 \mathrm{~mol} \%$ AS to be somewhat higher than the positive control. As shown in Figure 5, the addition of AE to the adjuvant mix was rarely positive.

3.3. Maturation of DCs. Loss of ability to take up dextran was used to assess the extent of activation of DCs exposed in vitro to the various archaeosomes (lacking antigen) (Figure 8). LPS served as a positive control. Activation was similar for LPS, M. smithii archaeosomes, and the combination 


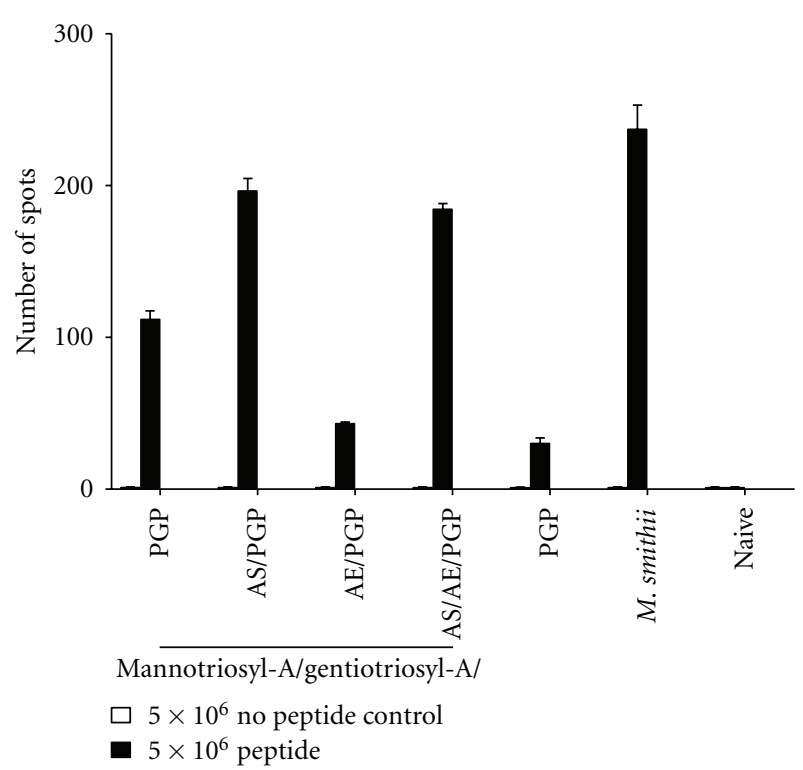

FIGURE 5: Elispot assay showing a relationship between adjuvant activity of glycosylarchaeol/PGP archaeosomes, archaetidylserine (AS), and archaetidylethanolamine (AE). Mol\% compositions for OVA-archaeosome vaccines were mannotriosyl-A/gentiotriosylA/PGP (22.5/22.5/55), mannotriosyl-A/gentiotriosyl-A/AS/PGP (22.5/ 22.5/30/25), mannotriosyl-A/gentiotriosyl-A/AE/PGP (22.5/ 22.5/5/50), mannotriosyl-A/gentiotriosyl-A/AS/AE/PGP (22.5/ $22.5 / 30 / 5 / 20$ ). Assays were conducted on splenic cells of mice 6 weeks post first immunization.

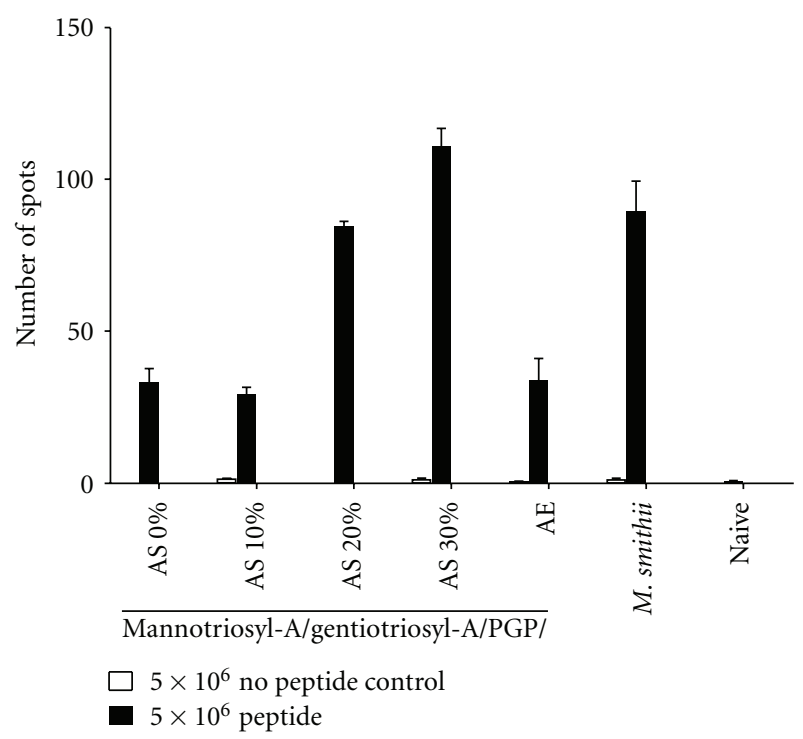

FIGURE 6: Elispot assay showing a relationship between mol\% AS in a triglycosyl-A/PGP archaeosome and CD8 adjuvant activity. Mannotriosyl-A and gentiotriosyl-A were always $22.5 \mathrm{~mol} \%$ each. AS was varied as shown at $0,10,20$, and $30 \mathrm{~mol} \%$, with PGP making the remainder of each composition. For comparison, archaeosomes containing $5 \mathrm{~mol} \% \mathrm{AE}$ and $M$. smithii total polar lipid archaeosomes are included.

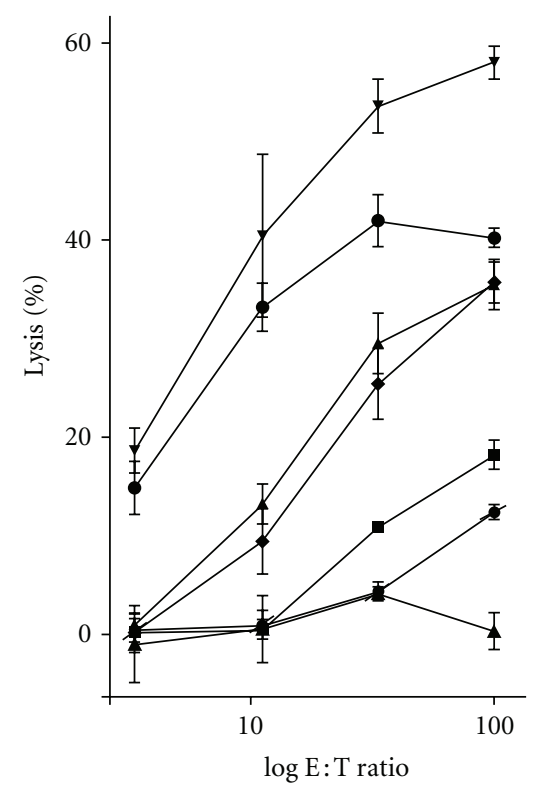

\footnotetext{
$\rightarrow$ Mannotriosyl-A/gentiotriosyl-A/PGP/AS-30\% $(18.18 \mu \mathrm{g} / \mathrm{mg})$

- M. smithii $(22.9 \mu \mathrm{g} / \mathrm{mg})$

- Mannotriosyl-A/gentiotriosyl-A/PGP/AS-20\% $(23.08 \mu \mathrm{g} / \mathrm{mg})$

- Mannotriosyl-A/gentiotriosyl-A/PGP/AE-5\% (13.21 $\mu \mathrm{g} / \mathrm{mg})$

- - Mannotriosyl-A/gentiotriosyl-A/PGP/AS-10\% (15.3 $\mu \mathrm{g} / \mathrm{mg})$

- - Mannotriosyl-A/gentiotriosyl-A/PGP $(10 \% \mu \mathrm{g} / \mathrm{mg})$

$\triangle$ Naive
}

Figure 7: Cytotoxic T lymphocyte (CTL) lysis assay was used to assess the same populations of splenic cells as in Figure 6. Loadings of the OVA antigen are shown also in this figure. EL- 4 control targets not expressing SIINFEKL gave $<10 \%$ lysis in all cases (not shown).

of gentiotriosylarchaeol/mannotriosylarchaeol/PGP with or without AS. Evidence for AS activation could be seen, however, by comparing AS/PGP (30/70 mol\%) archaeosomes to either of AE/PGP (5/95 mol\%), gentiotriosylarchaeol/PGP, or mannotriosylarchaeol/PGP archaeosomes.

3.4. Short and Long-Term Protective Immunity. M. smithii total polar lipid archaeosomes are capable of adjuvanting a $\mathrm{CD}^{+} \mathrm{T}$ cell response that is long-lasting and provides protection in a solid tumour model in mice $[11,18]$. Here we compare immune responses to protection in mice immunized with the various synthetic archaeosomes-OVA. Short-term immunity was assessed in animals $(n=5)$ by challenge with EG.7 tumour cells 4.5 weeks after the second immunization (Figure 9(a)). Protection could be correlated to the $\mathrm{CD}^{+} \mathrm{T}$ cell immune responses achieved (see previous figures). Naive mice are considered unprotected and succumbed to tumour growth early. PGP-OVA archaeosomes showed only limited protection, with best protection achieved with mannotriosylarchaeol/gentiotriosylarchaeol/AS/PGP OVAarchaeosomes. Longer-term immunity was assessed by injection of EG.7 cells 14 weeks following the second immunization (Figure 9(b)). Nonimmunized naive mice and OVA immunizations (no adjuvant) showed no protection, 


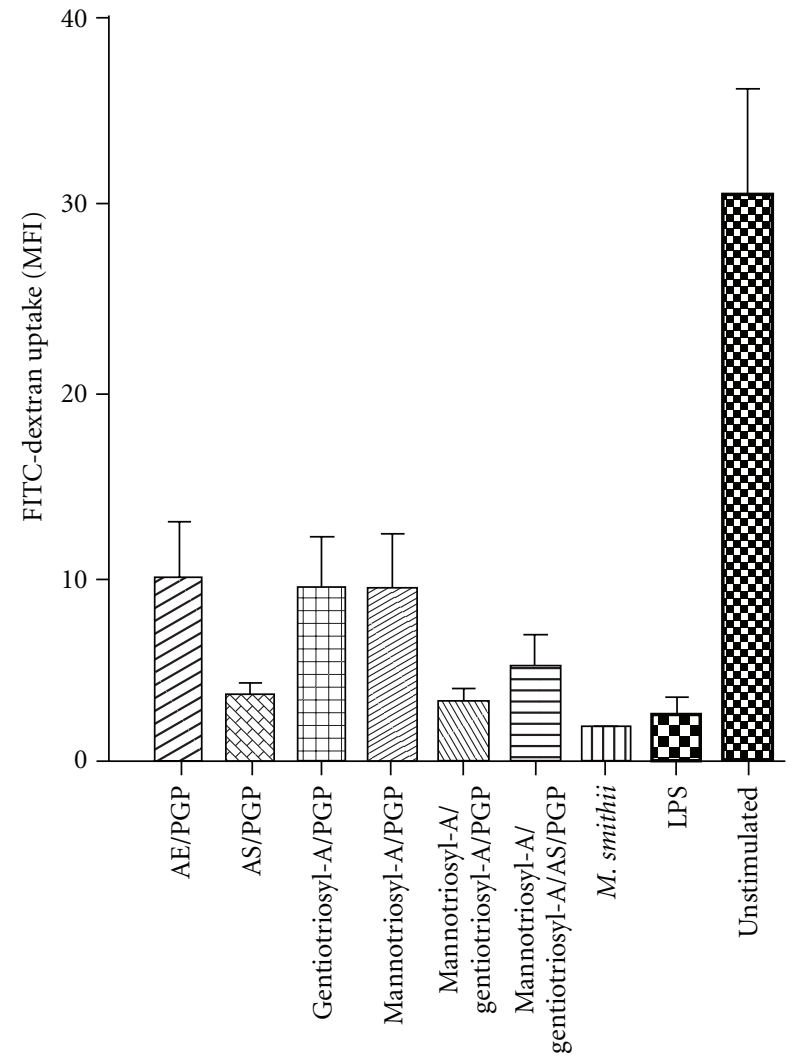

Figure 8: Maturation of dendritic cells (DCs) upon treatment with archaeosomes as measured by decrease of FITC-dextran uptake. Bone marrow DCs treated with archaeosomes in vitro were compared for their ability to take up FITC-dextran. The results depict the mean $\triangle \mathrm{MFI}\left(37-4^{\circ} \mathrm{C}\right)$. Data represent means $\pm \mathrm{SD}$ of triplicate cultures as indicated.

whereas the optimized archaeosome gave protection similar to the positive control.

\section{Discussion}

A goal of this study was to define an archaeosome adjuvant composition suitable for human application through use of synthetic archaeol-based lipids. Past studies on the mechanism of archaeosomes made from the total polar lipids of various archaea have shown that adjuvant activity occurs at the level of the antigen-presenting dendritic and macrophages cells $[19,24]$. Glycolipids in these total polar lipid mixtures may presumably serve as effective adjuvant ingredients as they can target specific receptors on antigenpresenting cells $[9,25,26]$.

As glycolipids are uncharged, a stable bilayer does not form when attempts are made to prepare pure glycolipidliposome based vaccines. This can be achieved, as is the case for natural polar lipids consisting of both glyco and phospholipids, by including phospholipids in the glycolipid formulation [9]. Because inclusion of nonarchaeal lipids such as dipalmitoyl phosphatidylglycerol into archaeosomes results in decline in longer-term $\mathrm{CD}^{+} \mathrm{T}$ cell mediated immune responses [15], we used the diacidic extreme halophile lipid, PGP, in our synthetic glycoarchaeol formulations.

A series of mannosylarchaeols synthesized to have from 1 to 5 sugar units, hydrated best and gave best adjuvant activity at 3 or 4 linear sugar units [16]. Similarly, we found gentiotriosylarchaeol to be a better adjuvant than gentiobiosylarchaeol. Further, the additive adjuvant effect obtained by inclusion of both gentiotriosylarchaeol and mannotriosylarchaeol suggests multiple positive interactions with receptors, to account for an observed increased activation of antigen-presenting dendritic cells (Figure 8). This additive effect of glycosylarchaeols required that the archaeosome preparation be hydrated with all lipids present, suggesting that the various head groups on the archaeosome surface were presented simultaneously to multiple receptors in vivo.

Archaetidylserine (AS) as a component of gentiotriosylarchaeol/mannotriosylarchaeol/PGP archaeosomes increased the $\mathrm{CD}^{+} \mathrm{T}$ cell immune response to entrapped antigen in a concentration dependent manner, without significantly enhancing the antibody response (Figures 6-7). M. smithii total polar lipid archaeosomes contain AS and their endocytosis has been linked to interaction with the phosphatidylserine receptor of antigen-presenting cells [12]. The pathway of cross-presentation of antigen carried in $M$. smithii archaeosomes occurs at the late phagolysosome stage [12] when calcium is internalized [27], suggesting that AS also contributes to membrane fusion promoted by calcium in analogy to phosphatidylserine [23]. Fusion of archaeosomes with the phagolysosome membrane would contribute to export of antigen to the cytosol and provide access to the MHC class-I presentation pathway.

The longevity of $\mathrm{CD} 8^{+} \mathrm{T}$ cell memory induced by total polar lipid archaeosomes of M. smithii and Thermoplasma acidophilum is generally not found in archaeosomes prepared from total polar lipids of extreme halophiles, that lack caldarchaeols [6]. For this reason, it was proposed that longterm $\mathrm{CD}^{+} \mathrm{T}$ cell memory may require the presence of high proportions of caldarchaeol membrane-stabilizing lipids. In this study we found that protective $\mathrm{CD} 8^{+} \mathrm{T}$ cell memory responses could be induced in mice immunized with antigen-archaeosomes lacking caldarchaeols. This further indicated the importance of head group in lipid composition of an all archaeol-based adjuvant [9].

\section{Conclusion}

The immune response to antigen may be preferentially directed to either MHC-I (CD8) or MHC-II (CD4) presentations by selection of the head group(s) of an archaeolbased adjuvant. PGP archaeosomes direct antigen primarily to an antibody pathway of response as suggested previously [10]. Additions of glycoarchaeols to PGP archaeosomes enhance greatly the MHC class I pathway of antigen presentation producing the $\mathrm{CD} 8^{+} \mathrm{T}$ cell response. Combination of gentiotriosyl- and mannotriosylarchaeols in the archaeosome adjuvant enhanced the $\mathrm{CD} 8^{+} \mathrm{T}$ cell response over 


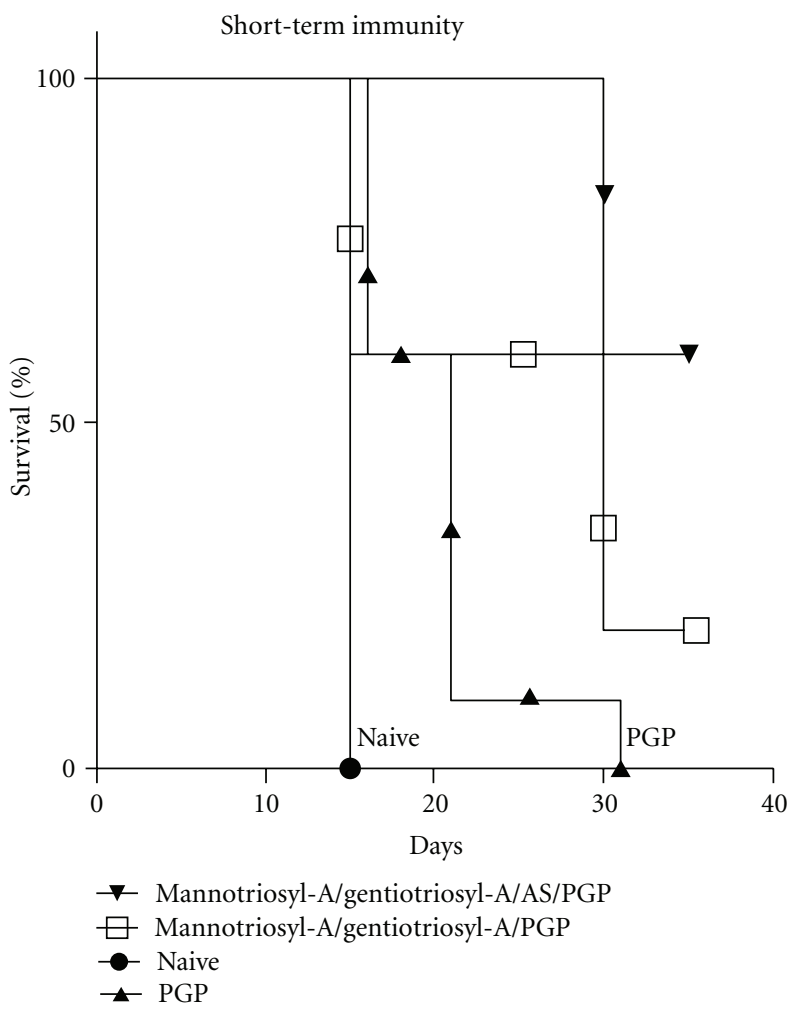

(a)

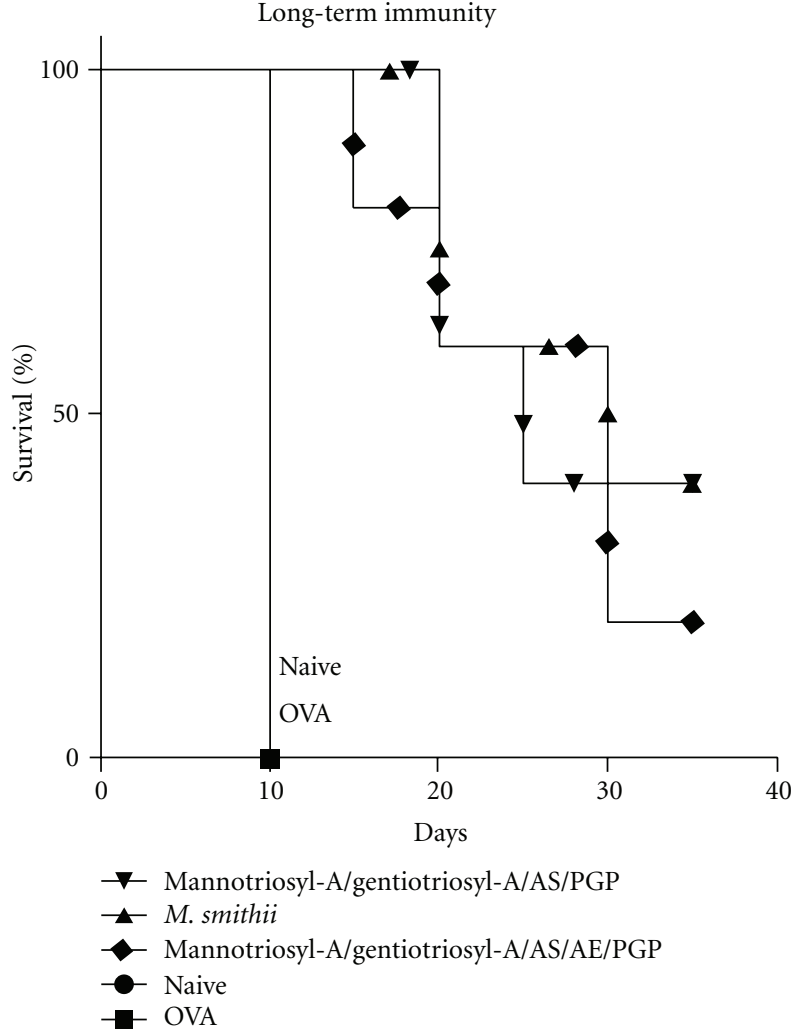

(b)

FIgURE 9: Protection of mice immunized with archaeosomes of various lipid compositions in a solid tumour model. Groups $(n=5)$ of unvaccinated mice (naive) or mice vaccinated with various OVA-archaeosomes were challenged with a subcutaneous injection of EG.7 cells (time zero) either 4.5 weeks (panel (a)) or 14 weeks (panel (b)) following their last vaccination.

either alone, and the additional presence of archaetidylserine was of further benefit. Finally, long-term immunity was obtained in an archaeol-based lipid archaeosome lacking caldarchaeols. We conclude that for a cancer or intracellular pathogen vaccine where a $\mathrm{CD} 8^{+} \mathrm{T}$ cell response is needed, a favorable archaeosome composition is gentiotriosylarchaeol, mannotriosylarchaeol, AS, and PGP in mol\% ratio 22.5/22.5/30/25.

\section{Acknowledgments}

Halobacterium salinarum biomass was produced by $\mathrm{Mr}$. John Shelvey in the NRC Bacterial Culture Facility. Animal Husbandry and the bleeding of mice were conducted in the NRC Animal Facility under the guidance of Dr. Craig Bihun. The final art work for figures was done by Mr. Tom Devecseri.

\section{References}

[1] G. D. Sprott, C. J. Dicaire, L. P. Fleming, and G. B. Patel, "Stability of liposomes prepared from archaeobacterial lipids and phosphatidylcholine mixtures," Cells and Materials, vol. 6, no. 1-3, pp. 143-155, 1996.

[2] C. G. Choquet, G. B. Patel, T. J. Beveridge, and G. D. Sprott, "Stability of pressure-extrudes liposomes made from archaeobacterial ether lipids," Applied Microbiology and Biotechnology, vol. 42, no. 2-3, pp. 375-384, 1994.

[3] A. Omri, B. Makabi-Panzu, B. J. Agnew, G. D. Sprott, and G. B. Patel, "Influence of coenzyme Q10 on tissue distribution of archaeosomes, and pegylated archaeosomes, administered to mice by oral and intravenous routes," Journal of Drug Targeting, vol. 7, no. 5, pp. 383-392, 2000.

[4] K. Ring, B. Henkel, A. Valenteijn, and R. Gutermann, "Studies on the permeability and stability of liposomes derived from a membrane spanning bipolar archaebacterial tetraetherlipid," in Liposomes as Drug Carriers, K. H. Schmidt, Ed., pp. 101123, Georg Thieme, Stuttgart, Germany, 1986.

[5] G. D. Sprott, D. L. Tolson, and G. B. Patel, "Archaeosomes as novel antigen delivery systems," FEMS Microbiology Letters, vol. 154, no. 1, pp. 17-22, 1997.

[6] L. Krishnan and G. D. Sprott, "Archaeosomes as selfadjuvanting delivery systems for cancer vaccines," Journal of Drug Targeting, vol. 11, no. 8-10, pp. 515-524, 2003.

[7] D. L. Tolson, R. K. Latta, G. B. Patel, and G. D. Sprott, "Uptake of archaeobacterial liposomes and conventional liposomes by phagocytic cells," Journal of Liposome Research, vol. 6, no. 4, pp. 755-776, 1996.

[8] G. D. Sprott, S. Sad, L. P. Fleming, C. J. Dicaire, G. B. Patel, and L. Krishnan, "Archaeosomes varying in lipid composition differ in receptor-mediated endocytosis and differentially adjuvant immune responses to entrapped antigen," Archaea, vol. 1, no. 3, pp. 151-164, 2003. 
[9] D. G. Sprott, C. J. Dicaire, J. P. Côté, and D. M. Whitfield, "Adjuvant potential of archaeal synthetic glycolipid mimetics critically depends on the glyco head group structure," Glycobiology, vol. 18, no. 7, pp. 559-565, 2008.

[10] D. M. Whitfield, S. H. Yu, C. J. Dicaire, and G. D. Sprott, "Development of new glycosylation methodologies for the synthesis of archaeal-derived glycolipid adjuvants," Carbohydrate Research, vol. 345, no. 2, pp. 214-229, 2010.

[11] L. Krishnan, S. Sad, G. B. Patel, and G. D. Sprott, "Archaeosomes induce long-term $\mathrm{CD}^{+}$cytotoxic $\mathrm{T}$ cell response to entrapped soluble protein by the exogenous cytosolic pathway, in the absence of CD4 $4^{+} \mathrm{T}$ cell help," Journal of Immunology, vol. 165, no. 9, pp. 5177-5185, 2000.

[12] K. Gurnani, J. Kennedy, S. Sad, G. D. Sprott, and L. Krishnan, "Phosphatidylserine receptor-mediated recognition of archaeosome adjuvant promotes endocytosis and MHC class I cross-presentation of the entrapped antigen by phagosometo-cytosol transport and classical processing," Journal of Immunology, vol. 173, no. 1, pp. 566-578, 2004.

[13] G. D. Sprott, S. Larocque, N. Cadotte, C. J. Dicaire, M. McGee, and J. R. Brisson, "Novel polar lipids of halophilic eubacterium Planococcus $\mathrm{H} 8$ and archaeon Haloferax volcanii," Biochimica et Biophysica Acta, vol. 1633, no. 3, pp. 179-188, 2003.

[14] G. D. Sprott, G. B. Patel, and L. Krishnan, "Archaeobacterial ether lipid liposomes as vaccine adjuvants," Methods in Enzymology, vol. 373, article 11, pp. 155-172, 2003.

[15] C. J. Dicaire, S. H. Yu, D. M. Whitfield, and G. D. Sprott, "Isopranoid- and dipalmitoyl-aminophospholipid adjuvants impact differently on longevity of CTL immune responses," Journal of Liposome Research, vol. 20, no. 4, pp. 304-314, 2010.

[16] D. M. Whitfield, E. E. Eichler, and G. D. Sprott, "Synthesis of archaeal glycolipid adjuvants-what is the optimum number of sugars?" Carbohydrate Research, vol. 343, no. 14, pp. 2349 2360, 2008.

[17] L. Krishnan, C. J. Dicaire, G. B. Patel, and G. D. Sprott, "Archaeosome vaccine adjuvants induce strong humoral, cellmediated, and memory responses: comparison to conventional liposomes and alum," Infection and Immunity, vol. 68, no. 1, pp. 54-63, 2000.

[18] L. Krishnan, S. Sad, G. B. Patel, and G. D. Sprott, "Archaeosomes induce enhanced cytotoxic $\mathrm{T}$ lymphocyte responses to entrapped soluble protein in the absence of interleukin 12 and protect against tumor challenge," Cancer Research, vol. 63, no. 10, pp. 2526-2534, 2003.

[19] L. Krishnan, S. Sad, G. B. Patel, and G. D. Sprott, "The potent adjuvant activity of archaeosomes correlates to the recruitment and activation of macrophages and dendritic cells in vivo," Journal of Immunology, vol. 166, no. 3, pp. 1885-1893, 2001.

[20] M. Kato, T. K. Nell, D. B. Fearnley, A. D. McLellan, S. Vuckovic, and D. N. J. Hart, "Expression of multilectin receptors and comparative FITC-dextran uptake by human dendritic cells," International Immunology, vol. 12, no. 11, pp. 1511-1519, 2000.

[21] V. A. Fadok, D. L. Bratton, D. M. Rose, A. Pearson, R. A. B. Ezekewitz, and P. M. Henson, "A receptor for phosphatidylserine-specific clearance of apoptotic cells," Nature, vol. 405, no. 6782, pp. 85-90, 2000.

[22] S. Martens and H. T. McMahon, "Mechanisms of membrane fusion: disparate players and common principles," Nature Reviews Molecular Cell Biology, vol. 9, no. 7, pp. 543-556, 2008.

[23] G. D. Sprott, J. P. Côté, and H. C. Jarrell, "Glycosidase-induced fusion of isoprenoid gentiobiosyl lipid membranes at acidic pH," Glycobiology, vol. 19, no. 3, pp. 267-276, 2009.
[24] L. Krishnan and G. D. Sprott, "Archaeosome adjuvants: immunological capabilities and mechanism(s) of action," Vaccine, vol. 26, no. 17, pp. 2043-2055, 2008.

[25] R. N. Coler, S. Bertholet, M. Moutaftsi et al., "Development and characterization of synthetic glucopyranosyl lipid adjuvant system as a vaccine adjuvant," PLoS ONE, vol. 6, no. 1, article e16333, 2011.

[26] I. Matsunaga and D. B. Moody, "Mincle is a long sought receptor for mycobacterial cord factor," Journal of Experimental Medicine, vol. 206, no. 13, pp. 2865-2868, 2009.

[27] K. A. Christensen, J. T. Myers, and J. A. Swanson, "pHdependent regulation of lysosomal calcium in macrophages," Journal of Cell Science, vol. 115, Part 3, pp. 599-607, 2002. 

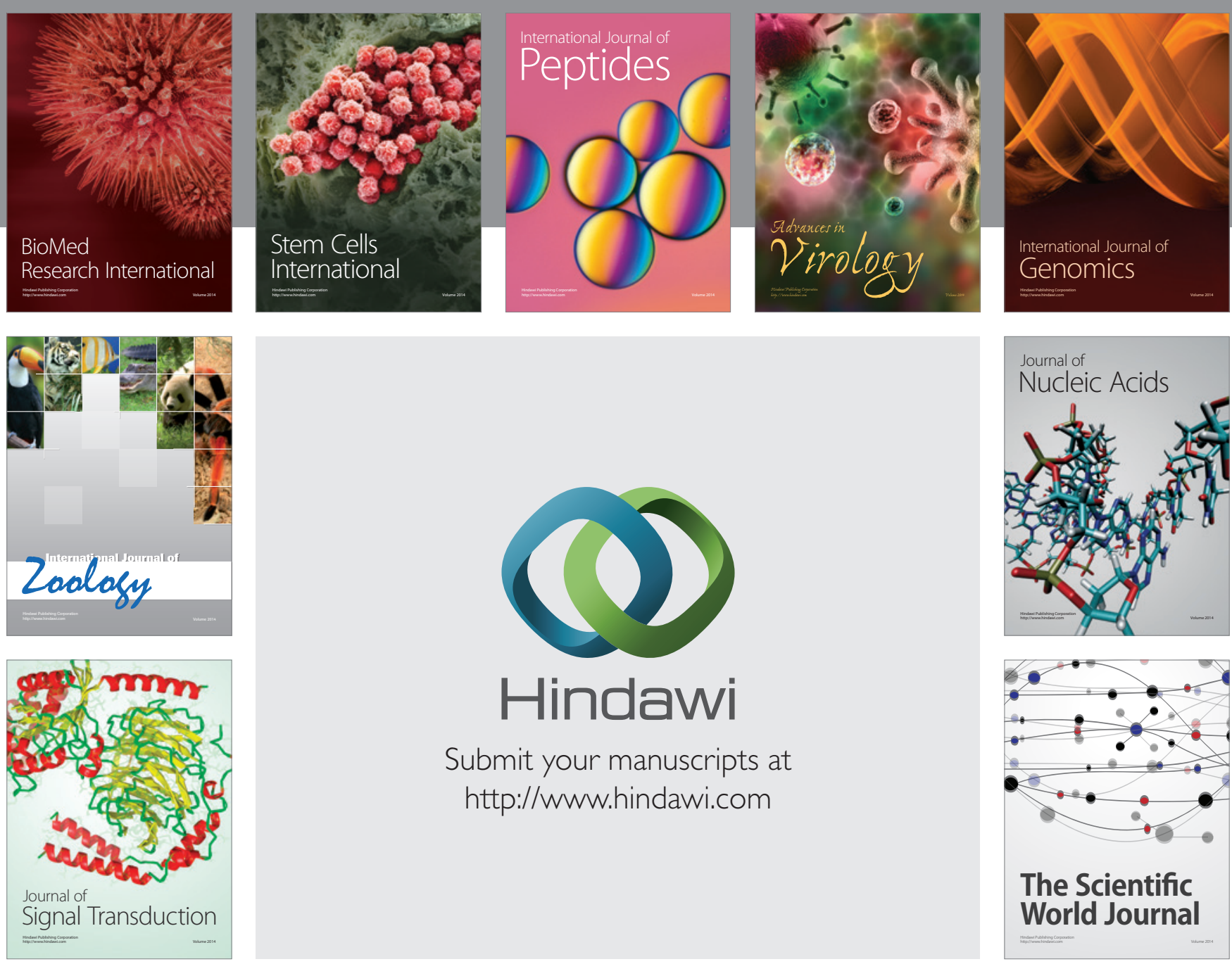

Submit your manuscripts at

http://www.hindawi.com
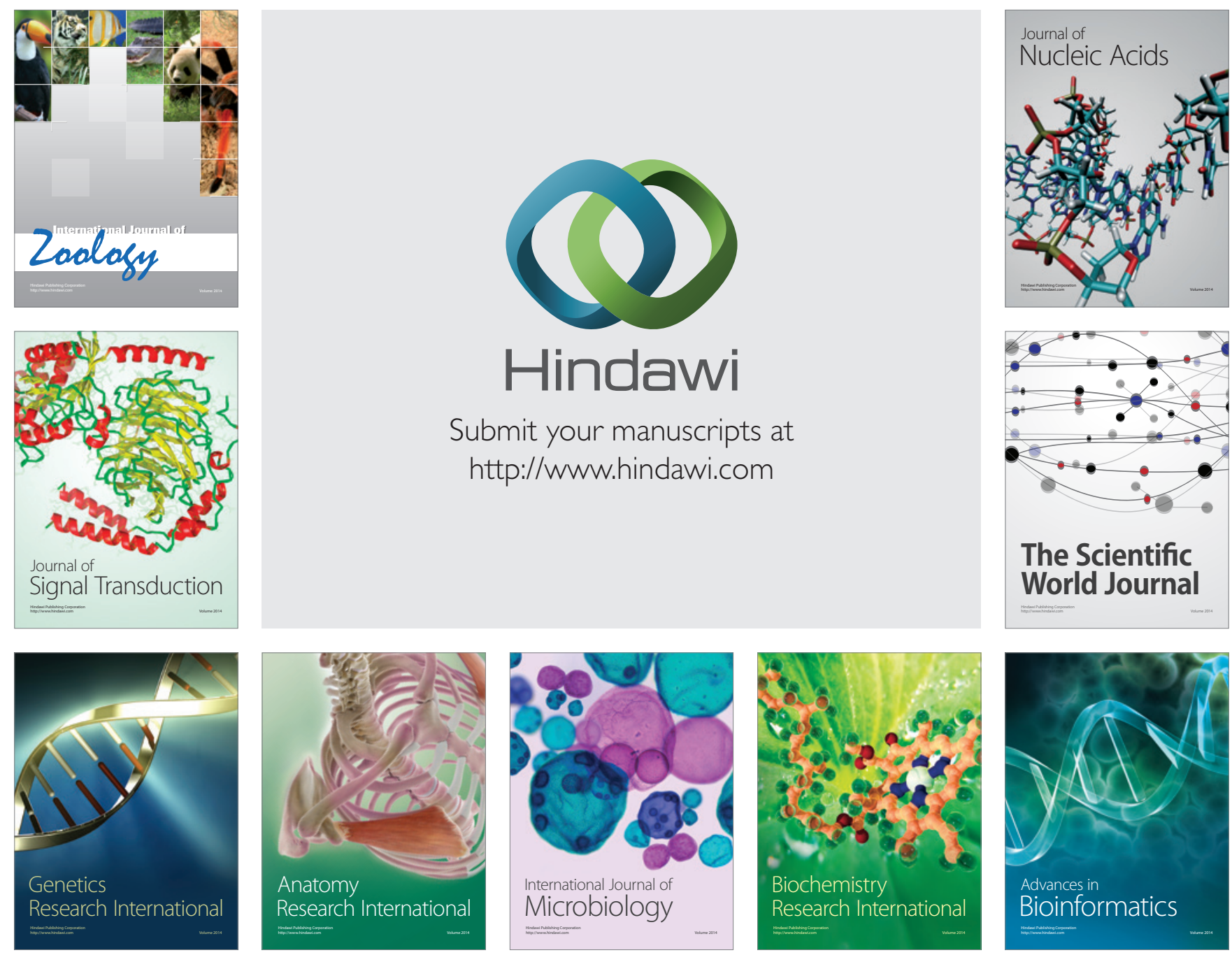

The Scientific World Journal
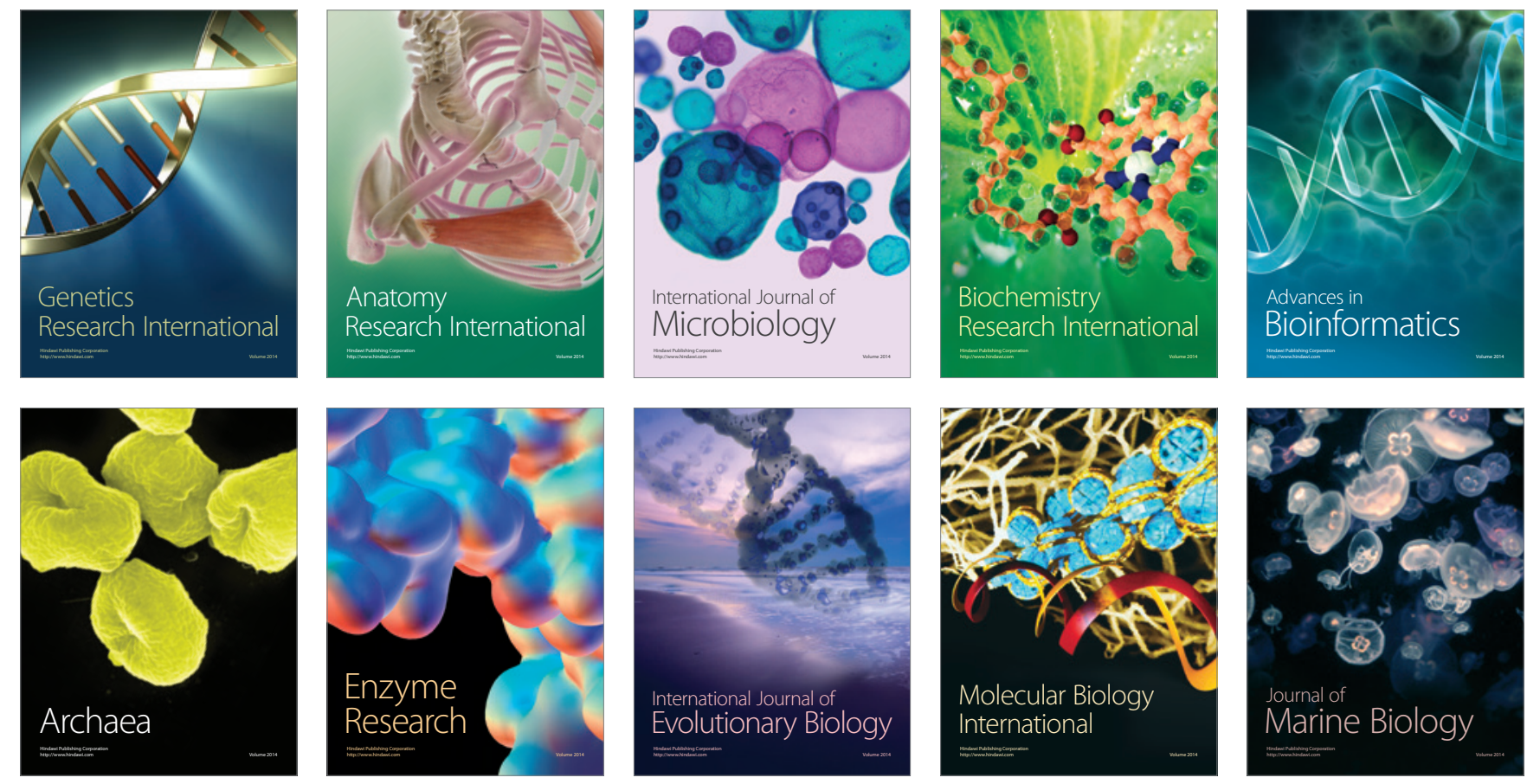